\title{
Effects of Serotonin and Cortisol Hormones on Development of Diabetes Mellitus Type 2 Disease
}

\section{Authors}

Mustafa Saleam Khalaf / AL-Rasheed College University / Iraq

E-mail : dr.mustafa_saleam@alrasheedcol.edu.iq

Mobile: 00964-7725503941 


\begin{abstract}
Diabetes Mellitus (DM) type 2 is chronic metabolic disease that characterized by elevation of serum glucose level (hyperglycemia) due to insulin hormone reduce or insulin cells resistance, that generate many complications such as retinopathy. Serotonin is hormonal neurotransmitter commonly found in brain cell but it also present in beta cells of pancreas. It is key hormone that stabilizes mood, feelings of well-being, and happiness. cortisol hormone is steroid hormone product and release by some of adrenal gland layers with a diurnal cycle manner and consider as primary stress hormone, it play role in many functions in body such as bio-molecular metabolisms . The objective of the study is the effects of serotonin and cortisol hormones on development of DM type 2 disease. Also the present study
\end{abstract}

Included this study compared between un-control DM type 2 patients (group 1) and controls persons (group 2), all individuals in this study were age 50-60 years of both genders .All individuals were measured serum serotonin and cortisol hormones level with focus on present of depression or not .Results of study shows reduce of serum serotonin concentration level with increase of cortisol concentration level in uncontrol DM type 2 group compare with control group. Also the un-control DM type 2 group have depression situation when compare with control group

This study confirms that decreased serum serotonin concentration level and increase of cortisol concentration level can act as support to development of DM type 2 disease

Keywords: Cortisol hormone, Serotonin Hormone, Depression and DM type 2 


\section{Introduction}

Diabetes mellitus (DM) type 2 is chronic disease commonly at old age population characterized by increase of blood glucose level (hyperglycemia), the age of people suffer of this disease are more than 40 years old . DM type 2 caused by tow reasons (1):

-Firstly insufficient secretion of insulin hormone by pancreases

-Second human cells resistance to insulin

Also, There are various signs and symptoms of DM type 2 disease for example hungry, blurry vision and others, and DM type 2 has many complications because hyperglycemia for long period such as diabetes nephropathy, retinopathy and others (2)

Cortisol is hormone secretion by special adrenal gland layers called cortex layers by effect of feedback mechanism from pituitary gland via Adrenocorticotropic hormone $(\mathrm{ACTH})$, and it consider as primary stress hormone .Cortisol hormone targeted all body cells to do many functions such as blood glucose regulation, reduce inflammation and others (3) . Serotonin is hormonal neurotransmitters made from tryptophan, that consider as essential amino acid in body. The human body need tryptophan and it enter to body through foods such as nuts and red meat (4). This hormone has important role at stabilizes our mood, feelings of well-being, and happiness. It act to enable the nervous to communicate with each other in nervous system cells. However, the individual suffer from depression stat if serotonin become low level in brain and nervous cells but If has too much serotonin, it can lead to excessive nerve cell activity (5)

\section{Material and Methods}

This study designed according to selection of tow groups : -Group 1 : un-control DM type 2 patients (No. 30 persons)

-Group 2: healthy individuals (No. 30 persons) as controls

All individuals in this study were age between 50 to 60 years of both genders, and done of this study in the national Center for Diabetes - Iraq after agree Ethical Standards Committee in the Al-Rasheed university .college for this study

The present study included measurement tow parameters serum cortisol and serum serotonin hormones, in addition this study focused on psychological state of all individuals when selection. ELISA technique used to these measurement , ELISA kits are serotonin SKU: SER39K01 Eagle Biosciences company -USA and cortisol (ab108665) Abcam company -USA respectively. The serum was obtain via immediately . separation of blood without any preservative factors at P.M. period 
Statistic Analysis

$\mathrm{T}$-test used for compared between quantity study and Chi-square test used for compared between quality study in this study ,p-value >0.05 consider as significant value, also used correlation coefficient $(r)$ to explain correlation between parameters

\section{Results}

The current study include comparison between un-control DM type 2 and control groups by used serum serotonin and cortisol hormones levels parameters and find correlation between them. Also include comparison between these groups according to present or not of depression by clinical examinations. This study results shown significant differences between two groups according to suffer of depression, serum cortisol and serotonin hormones level, and revers correlation between serum cortisol and serotonin hormones levels .This result presented elevated of depression state and serum cortisol level in un-control DM type 2 group, in addition reduce of serum serotonin level in un-control DM type 2 group when compare with control group. Table 1 and 2 .

Figure 1 .

Table 1: Comparison of serum serotonin and cortisol hormones levels between uncontrol DM type 2 and control groups according to Mean \pm Standard deviation (SD ) by $\mathrm{T}$ - test statistic method

\begin{tabular}{|l|l|l|l|l|}
\hline Parameters & $\begin{array}{l}\text { Un-control } \\
\text { DM type 2 } \\
\text { (NO. 30 } \\
\text { individuals) } \\
\text { Mean+SD }\end{array}$ & $\begin{array}{l}\text { Control (NO. } \\
\text { individuals) } \\
\text { Mean+SD }\end{array}$ & P-value & $\mathrm{r}$ \\
\hline $\begin{array}{l}\text { Cortisol level } \\
(\mathrm{ng} / \mathrm{ml})\end{array}$ & $7.9 \pm 1.05$ & $5.4 \pm 0.97$ & $<0.05$ & -0.5 \\
\hline $\begin{array}{l}\text { Serotonin } \\
\text { level }(\mathrm{ng} / \mathrm{ml})\end{array}$ & $41.9 \pm 2.6$ & $74.2 \pm 5.8$ & $<0.05$ & \\
\hline
\end{tabular}


Table 2: Comparison of depression state between un-control DM type 2 and control groups according to percentages by Chi-square test statistic method

\begin{tabular}{|l|l|l|l|}
\hline & $\begin{array}{l}\text { Un-control DM } \\
\text { type 2 (NO. 30 } \\
\text { individuals) }\end{array}$ & $\begin{array}{l}\text { Control (NO. 30 } \\
\text { individuals) }\end{array}$ & P-value \\
\hline $\begin{array}{l}\text { Depression state } \\
\text { percent }\end{array}$ & $\begin{array}{l}\text { Yes 86\% } \\
\text { No 14\% }\end{array}$ & Yes 7\% 93\% & $<0.05$ \\
\hline
\end{tabular}

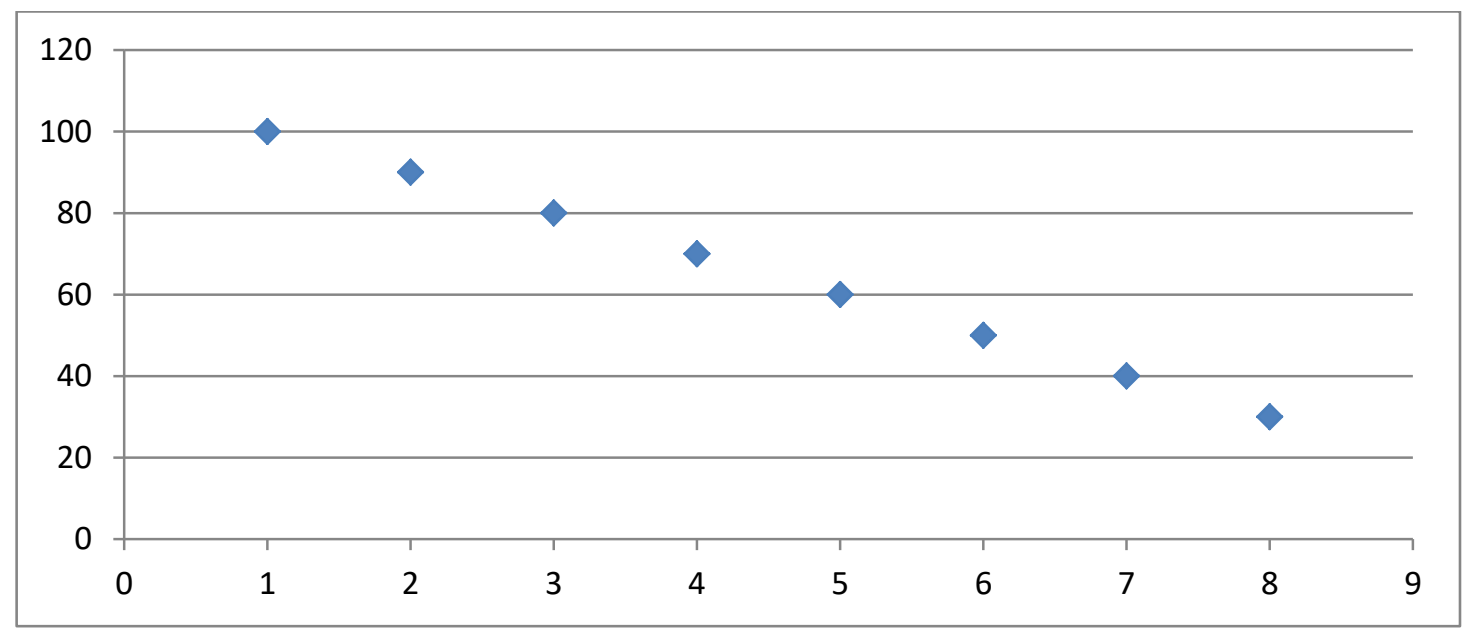

Figure 1: Revers correlation between serum serotonin and cortisol hormones levels in un-control DM type 2 group

\section{Discussion}

DM type 2 is chronic metabolic disease that characterized by elevation of serum glucose level (hyperglycemia) due to insulin hormone reduce or insulin cells resistance. This condition cant lead to many complications such as retinopathy, neuropathy and others (6). In the present study results show significant reduce serum serotonin level and increase serum cortisol level at un-control DM type 2 group when compare with control group, with revers correlation between parameters , also this study explain significant high percent of depression stat at un. control DM type 2 group when compare with control group Reduce of serotonin level at un-control DM type 2 group demonstrate that serotonin hormone have role in regulation of serum glucose level via 
insulin hormone regulation. Serotonin is neurotransmitter commonly found in brain cell but it also present in beta cells of pancreas, it made bond with enzymes (7). Insulin and serotonin before release storage in granules and release together. Serotonin covalently bonds to the GTP-ase, a reaction called "serotonylation," which is catalyzed by a transglutaminase enzyme. Intriguingly, GTP-ase also help regulate insulin secretion in the pancreas. This theory demonstrate in present study result, reduce of serotonin can lead to development of DM type 2 . The study result agree with Paulmann N, and et al 2009 \& Khoshnevisan K and et al 2021 that also confirm effect of serotonin on insulin secretion $(8,9)$

The DM type 2 patients when become un-control being bad feeling due to our know that DM has various healthy harmful complications, this felling stimulation worry feeling for patients these felling can called psychiatric stress. The patients stress can convert to depression when DM patient being more worry about his healthy, already the depression felling can start to stimulate the stress hormones, commonly is cortisol hormone that consider as primary stress hormone (10). The cortisol hormone is steroid hormone product and release by some of adrenal gland layers with a diurnal cycle manner, it play role in many functions in body such as regulation of immune response, blood pressure and biomolecular metabolisms. The effect of cortisol hormone on regulation of bio-molecular metabolisms shown in many of metabolic pathway ,commonly pathway is stimulate liver and muscle glycogenolysis and gluconeogenesis which occurs as a result of the action of cortisol . Glycogenolysis and gluconeogenesis are metabolic processes lead to increase of serum glucose level that can development of DM type 2 severity then lead to un-control serum glucose level (11). These theory also confirm in this study due to finding increase level of cortisol hormone with present depression stat in un-control DM type 2 group .this study agrre with Joseph JJ , and et al 2017 that demonstrated effect of depression on cortisol level that lead to DM development (12)

The serotonin decrease lead to DM type 2 development due to it effect on insulin secretion and stimulation depression stat of patients, this effect can elevation of cortisol level that also lead to elevation of serum glucose level and DM type 2 development depression of patients resulting from DM type 2 development. This study document revers correlation .between serotonin and cortisol level at DM type 2 patients for first time 


\section{Conclusion}

Concluded the current study that DM type 2 disease can development by decrease of serum serotonin hormone level and increase of serum cortisol hormone level

\section{References}

1-Cole JB, Florez JC. Genetics of diabetes mellitus and diabetes .complications. Nature reviews nephrology. 2020 Jul;16(7):377-90

2-Oguntibeju OO. Type 2 diabetes mellitus, oxidative stress and inflammation: examining the links. International journal of physiology, .pathophysiology and pharmacology. 2019;11(3):45

3-Katsu Y, Baker ME. Cortisol. InHandbook of hormones 2021 Jan 1 (pp. 947-949).

Academic Press

4-Muller CP, Cunningham KA. Handbook of the behavioral neurobiology .of serotonin. Academic Press; 2020 Jan 23

5-Francescangeli J, Karamchandani K, Powell M, Bonavia A. The serotonin syndrome: from molecular mechanisms to clinical practice. .International journal of molecular sciences. 2019 Jan;20(9):2288

6-Snelson M, de Pasquale C, Ekinci EI, Coughlan MT. Gut microbiome, prebiotics, intestinal permeability and diabetes complications. Best Practice \& Research Clinical Endocrinology \& Metabolism. 2021 Feb $.17: 101507$

7-Field SL, Marrero MG, Dado-Senn B, Skibiel AL, Ramos PM, Scheffler TL, Laporta J. Peripheral serotonin regulates glucose and insulin metabolism in Holstein dairy calves. Domestic Animal $\begin{array}{llll}\text { Endocrinology. } & 2021 & \text { Jan } & \end{array}$

8-Paulmann N, Grohmann M, Voigt JP, Bert B, Vowinckel J, Bader M, Skelin $M$, Jevšek $M$, Fink $H$, Rupnik $M$, Walther DJ. Intracellular serotonin modulates insulin secretion from pancreatic $\beta$-cells by protein .serotonylation. PLoS biology. 2009 Oct 27;7(10):e1000229

9-Khoshnevisan K, Baharifar H, Torabi F, Afjeh MS, Maleki H, Honarvarfard E, Mohammadi H, Sajjadi-Jazi SM, Mahmoudi-Kohan S, Faridbod F, Larijani B. Serotonin level as a potent diabetes biomarker based on electrochemical sensing: a new approach in a zebra fish model. .Analytical and bioanalytical chemistry. 2021 Mar;413(6):1615-27 
10-Joseph JJ, Golden SH. Cortisol dysregulation: the bidirectional link between stress, depression, and type 2 diabetes mellitus. Annals of the .New York Academy of Sciences. 2017 Mar;1391(1):20

11-Dias JP, Joseph JJ, Kluwe B, Zhao S, Shardell M, Seeman T, Needham BL, Wand GS, Kline D, Brock G, Castro-Diehl C. The longitudinal association of changes in diurnal cortisol features with fasting glucose: MESA. Psychoneuroendocrinology. 2020 Sep $.1 ; 119: 104698$

12-Joseph JJ, Golden SH. Cortisol dysregulation: the bidirectional link between stress, depression, and type 2 diabetes mellitus. Annals of the .New York Academy of Sciences. 2017 Mar;1391(1):20 